\title{
Heart rate variability in children with obstructive sleep apnea: a systematic review
}

\begin{abstract}
Obstructive Sleep Apnea (OSA) is a common respiratory disorder characterized by recurrent nocturnal episodes of breathing interruption due to the total or partial collapse of upper airway, and affects $1.2-5.7 \%$ of children. Hypoxia and hypercapnia episodes play a role at the OSA physiopathology and correlate with autonomic impairment. Heart rate variability is a non-invasive method to evaluate autonomic nervous system regulation and it's a promising marker for health and disease, such as cardiovascular and respiratory diseases. This study aimed to review whether the heart rate variability was altered in children with obstructive sleep apnea. We searched in five databases, including BIREME, Cochrane, Scholar Google, MEDLINE/PubMed and Periodicos CAPES. Reference lists were also analyzed. Only cross-sectional studies comparing the heart rate variability of OSA children with controls were included. Six studies (945 participants) met the inclusion criteria. All studies had some shortcomings which could compromise the results, such as sample size, unsatisfatory comparison of each group, statistical analysis and assessment of the outcomes. In general, OSA children had lower HRV than control group, reflecting an autonomic imbalance and sympathetic overflow.
\end{abstract}

Volume 4 Issue I - 2020

\author{
Vanessa Cristina Cunha Sequeira, ${ }^{1,2}$ Pamela \\ Martin Bandeira, ${ }^{2}$ João Carlos Moreno \\ Azevedo' \\ 'Neuroscience Postgraduate, Veiga de Almeida University, Brazil \\ ${ }^{2}$ Federal University of Rio de Janeiro, Brazil
}

Correspondence: Vanessa Cristina Cunha Sequeira, Federal University of Rio de Janeiro, Edson Saad Heart Institute, Rio de Janeiro, Rio de Janeiro, Brazil,Tel 5521992592194, Email vanessacunhac@gmail.com

Received: January 21, 2020 | Published: February 17, 2020

Keywords: heart rate variability, obstructive sleep apnea, autonomic nervous system

Abbreviations: OSA, obstructive sleep apnea; CNS, central nervous system; ANS, autonomic nervous system; HR, heart rate; HRV, heart rate variability; RSA, respiratory sinus arrhythmia; RDI, respiratory disturbance index

\section{Introduction}

Obstructive Sleep Apnea (OSA) is a common respiratory disorder characterized by recurrent nocturnal episodes of breathing interruption due to the total or partial collapse of upper airway ${ }^{1}$ and affects 1.2$5.7 \%$ of children. ${ }^{2}$ The peak of incidence occurs at 2-8 years and the most common cause of OSA in children is enlarged tonsils and adenoids. ${ }^{2,3}$ Moreover, OSA is associated with morbidity that involves central nervous system (CNS), cardiovascular and metabolic systems. ${ }^{4}$ The recurrent hypoxia is suggested as the main cause of altered autonomic nervous system (ANS) in those patients. ${ }^{5,6}$ The obstructive episodes lead not only to hypoxia, but also intermittent hypercapnia, which can modulate the autonomic nervous system of OSA patients. Main consequences of hypoxia and hypercapnia include increased of sympathetic tone and sympathetic responsiveness as well as sympathetic-parasympathetic imbalance. ${ }^{4}$ There is also evidence that OSA alters heart rate response and systemic blood pressure, which can contribute to cardiovascular morbidities when adults. ${ }^{5}$ To evaluate the integrity of ANS is commonly used a non-invasive method named heart rate variability (HRV). HRV represents the oscilations of heart rate (HR) and it's considered a measure of neurocardiac function that reflects ANS dynamics. ${ }^{7}$ Some pathologies, such as respiratory and cardiovascular diseases, shows lower HRV pattern, which is consistent with and abnormal adaptability of ANS, whereas healthy individuals exhibit higher HRV indices meaning an ANS adaptable and dynamically responsive to change. ${ }^{8}$ To address this issue, the aim of this study was to review whether heart rate variability was altered in children with obstructive sleep apnea.

\section{Methods}

This systematic review was performed according to the PRISMA ${ }^{9}$ statement to identify studies featuring children with obstructive sleep apnea and measures of HRV. This review was also registered at PROSPERO under CRD42019091540.

\section{Criteria for considering studies for this review}

Types of studies: only case-control studies that compared heart rate variability of children with obstructive sleep apnea and healthy controls at rest, either awake or sleeping.

Types of participants: children with obstructive sleep apnea, without clinical history of cardiovascular, respiratory and metabolic diseases, and without any cirurgical intervention for obstructive sleep apnea.

Types of interventions: there were no interventions, only observational studies were accepted at this review.

Types of outcomes measures: cardiac measures containing evaluation of heart rate variability.

1) Primary outcomes: altered linear and non-linear parameters of heart rate variability indicating autonomic dysfunction/ dysautonomia.

2) Secondary outcomes: altered respiratory measures, such as respiratory frequency.

\section{Search methods for identification of studies}

Five electronic databases were searched (last search date: January 19, 2018) including BIREME, MEDLINE, Periodicos CAPES, The Cochrane Library and Scholar Google. To ensure that all potential articles were included, an extensive set of search terms was used to 
describe the heart rate variability measure (eg, electrocardiography, arterial pulse, heart rate, heart rate variability, hrv, autonomic nervous system, parasympathetic nervous system, sympathetic nervous system, vagus nerve, cardio-autonomic) combined with obstructive sleep apnea terms (eg, apnea, obstructive sleep, osahs, obstructive sleep apnea, sleep apnea syndrome, sleep apnea hypopnea syndrome, sleep apnea syndrome, obstructive syndrome, sleep apnea obstructive syndrome, upper airway resistance sleep apnea, upper airway resistance sleep apnea syndrome). There were no considerations for date of publication, but the limitation for language was English, Spanish and Portuguese because of lack available resources for translation. The search outputs were managed using EndNote Web.

\section{Data collection and analysis}

\section{Selection of studies}

Two authors examined the reference lists of identified articles and selected independently the potentially relevant studies for full text reading. At the full text reading phase, the reviewers also independently evaluate the studies based on elegibility criteria of the population, study design and outcomes. There was no disagrement between the two authors at inclusion or exclusion of studies. Any disagrement would be solved by a third reviewer. To be included in this review, the studies had to evaluate HRV in children with obstructive sleep apnea and compare them with healthy controls. The exclusion criteria were:

a. Cardiac measures without heart rate variability;

b. Performed research on unconscious participants (eg, anesthetized children);

c. Recruited children had other pathological condition beyond OSA; and

d. HRV measures were performed after an intervention. A flowchart of the selection process is included as Figure 1.

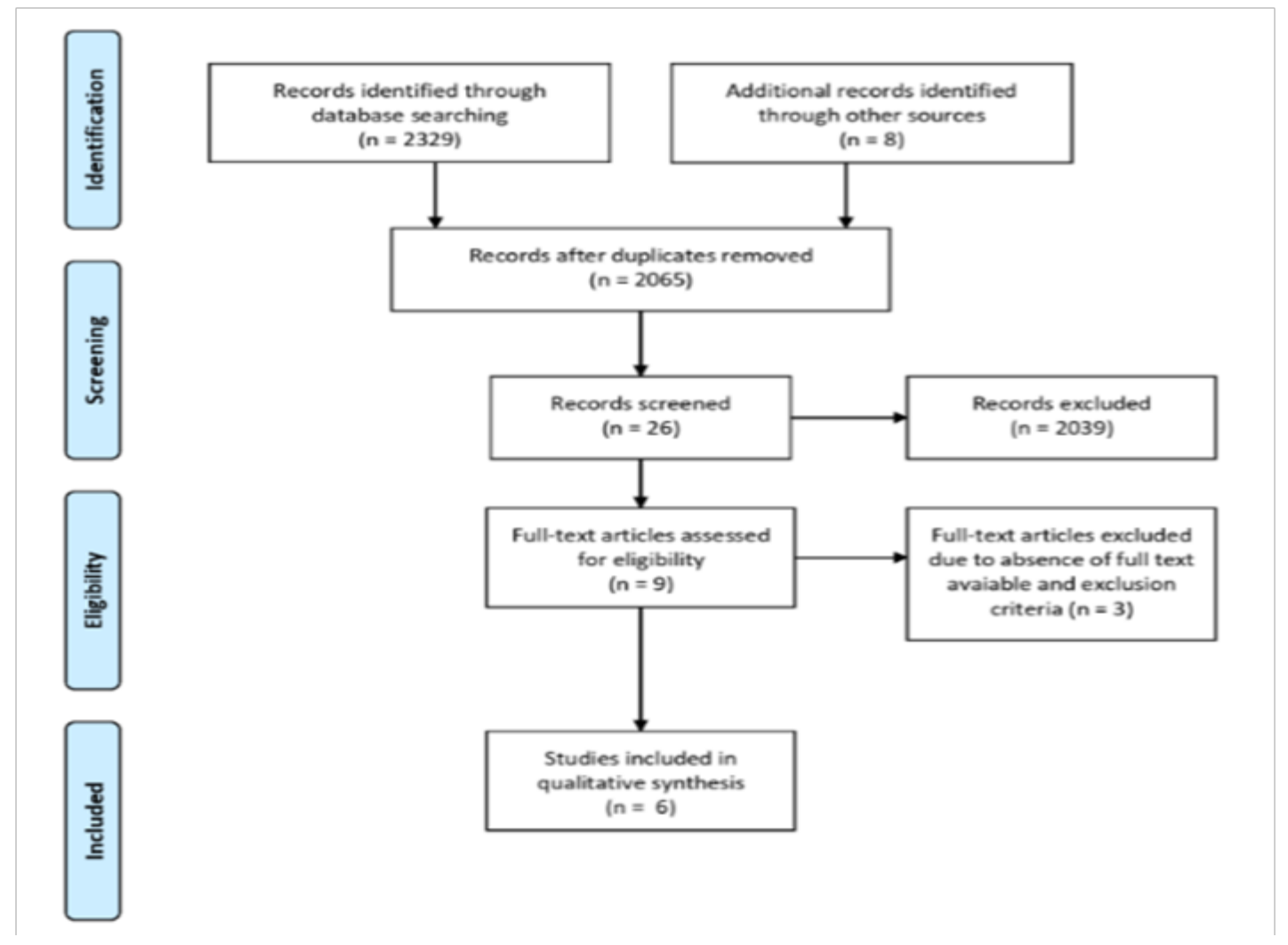

Figure I Flowchart of study selection.

n, number.

\section{Data extraction and managament}

Publications reporting survey data at the same location and period were carefully examined to avoid duplicate information. Data was independently extracted from each article. The variables extracted were: (a) country where the study was performed; (b) inclusion criteria for OSA; (c) sample characteristics; (d) HRV measurement data. Data extracted from the studies were presented at Tables $1 \& 2$. The first one shows the variables extracted from the participants and the last one demonstrates the type of HRV measurement and respective results.

\section{Assessment of risk of bias in included studies}

The Newcastle-Ottawa Quality Assessment Scale for Crosssectional studies ${ }^{10}$ was used for bias assessment. This scale includes three domains: selection, comparability and exposure. The assessment strategy of cross-sectional studies relies on the number of stars at each topic, so that selection can obtain 5(five) stars at maximum; comparability, 2(two) stars; and outcome, 3(three) stars. 
Table I Evidence table for the included studies

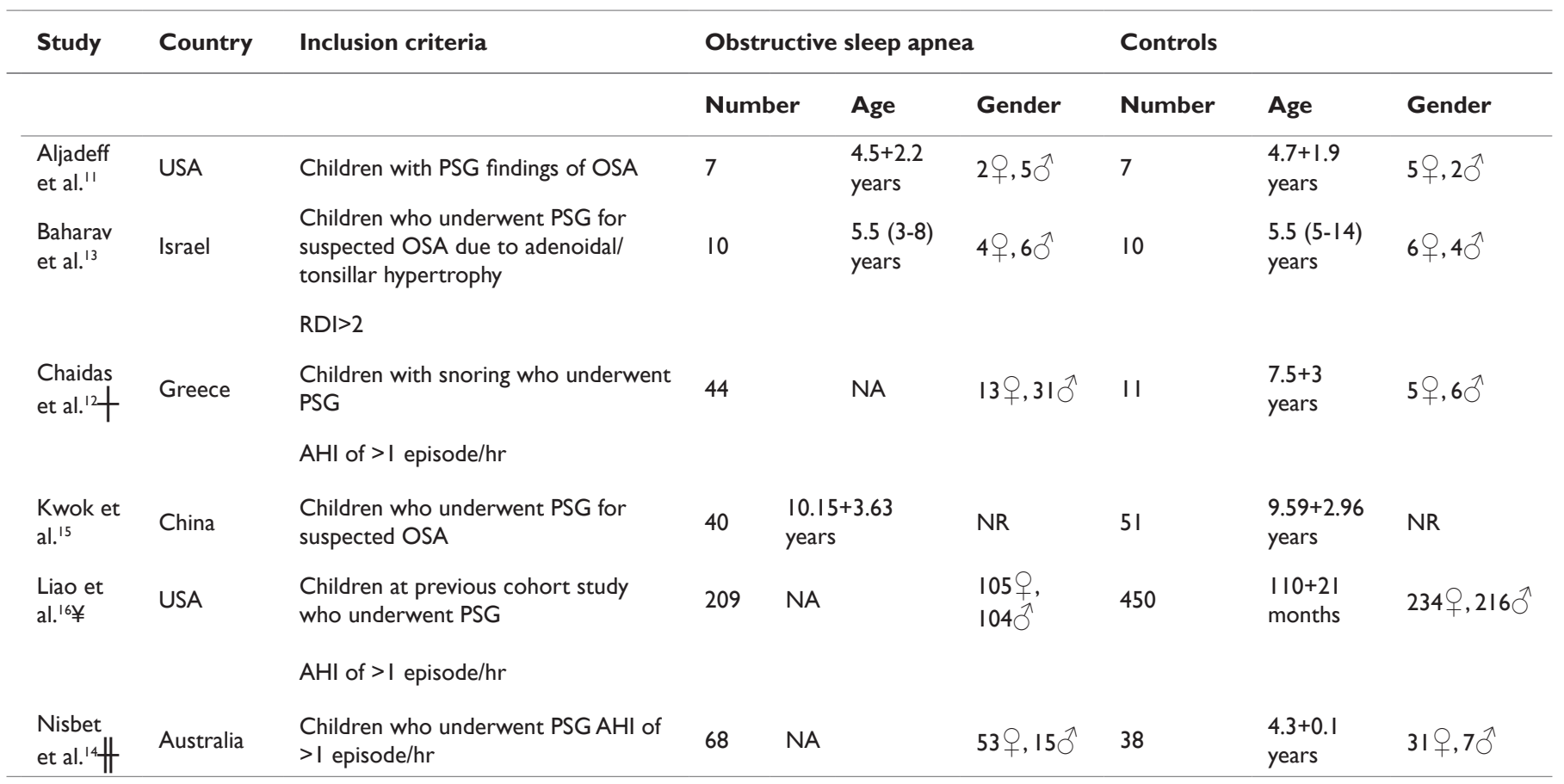

Data are reported as mean+SD (range)

†Recruited patients allocated in two groups: OSA with moderate-to-severe hypoxemia $\left(\mathrm{n}=20\right.$; age $6.5+3.9 ;$ gender $\left.69+14{ }^{\circ}\right)$ and OSA with mild hypoxemia $(n=24$, age $7+2.8$; gender 7 ○, $17 \precsim)$

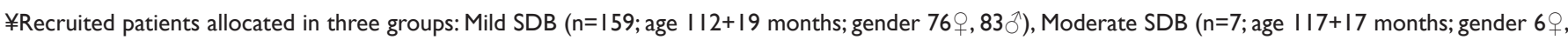
$\left.I^{\lambda}\right)$ and clinically diagnosed SDB ( $n=43$; age $106+26$ months; gender 23 ㅇ, 20 $\overbrace{}^{\Uparrow})$

\#Recruited patients allocated in three groups, but at this review was only considered two groups: Mild OSA ( $\mathrm{n}=39$; age 4.6+0.1; gender 29 9 , I0 ${ }^{\text {) }}$ ) and OSA

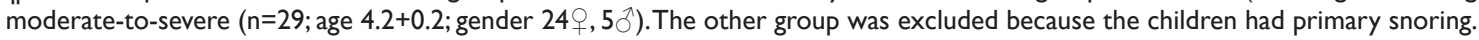

, female; $\widehat{O}$, male; AHI, apnea-hypopnea index; NA, not applicable; NR, not reported; OSA, obstructive sleep apnea; PSG, polysomnography; RDI, respiratory disturbance index; SDB, sleep-disordered breathing

Table 2 Methods of HRV measurement and obstructive sleep apnea findings

\begin{tabular}{|c|c|c|c|c|}
\hline Study & $\begin{array}{l}\text { Condition of } \\
\text { recording and } \\
\text { data length for } \\
\text { analysis }\end{array}$ & Derived HRV measures & $\begin{array}{l}\text { Secondary } \\
\text { outcomes (other } \\
\text { measures) findings }\end{array}$ & HRV and OSA findings \\
\hline $\begin{array}{l}\text { Aljadeff } \\
\text { et al. }{ }^{\prime \prime}\end{array}$ & $\begin{array}{l}\text { ECG during } \\
\text { sleep (time not } \\
\text { specified) }\end{array}$ & Poincaré Plot & NA & $\begin{array}{l}\text { Poincaré plots of children with OSA show } \\
\text { reduced next-interval variation following short and } \\
\text { intermediate R-R intervals but significantly enhanced } \\
\text { variation following long intervals compared to } \\
\text { control group }\end{array}$ \\
\hline $\begin{array}{l}\text { Baharav } \\
\text { et al. }{ }^{13}\end{array}$ & $\begin{array}{l}260 \text { seconds for } \\
\text { each sleep stage } \\
\text { (REM and non- } \\
\text { REM) and awake }\end{array}$ & $\begin{array}{l}\text { LF }(0.02-0.15 \mathrm{~Hz}), \mathrm{HF}(0.2-0.5 \mathrm{~Hz}) \\
\mathrm{LF} / \mathrm{HF}, \mathrm{TF}, \mathrm{LF} / \mathrm{T}, \mathrm{HF} / \mathrm{T}, \mathrm{ABI}\end{array}$ & $\begin{array}{l}\mathrm{ABI} \text { and } \mathrm{RDI} \text { were } \\
\text { positively correlated }\end{array}$ & $\begin{array}{l}\text { HF/T was lower in the OSA group compared with } \\
\text { the control group during all sleep-wake states, } \\
\text { whereas the LF/T is higher }\end{array}$ \\
\hline 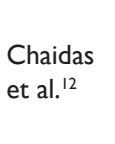 & $\begin{array}{l}\text { ECG during } \\
\text { sleep (time not } \\
\text { specified) }\end{array}$ & Poincaré plot & $\begin{array}{l}\text { Poincaré plot width } \\
\text { was negatively related } \\
\text { to respiratory arousal } \\
\text { index }\end{array}$ & $\begin{array}{l}\text { Poincaré plot width is reduced in children with OSA } \\
\text { and MS hypoxemia or mild hypoxemia than control } \\
\text { subjects }\end{array}$ \\
\hline & & & \multicolumn{2}{|c|}{$\begin{array}{l}\text { Ln-transformed morning urine norepinephrine-to-creatinine ratio were higher in } \\
\text { children with OSA and moderate-to-severe hypoxemia than controls }\end{array}$} \\
\hline $\begin{array}{l}\text { Kwok et } \\
\text { al. }^{15}\end{array}$ & $\begin{array}{l}\text { 60-min supine } \\
\text { ECG awake }\end{array}$ & $\begin{array}{l}\text { SDNN, SDANN, RMSSD, pNN50, } \\
\text { VLF (0.004-0.04 Hz), LF (0.04 -0.15 } \\
\text { Hz), HF (0.15-0.4 Hz), LF/HF, HF/T, } \\
\text { LF/T,TF }\end{array}$ & NA & $\begin{array}{l}\text { Mean pNN50 was lower in OSA group than non- } \\
\text { OSA group }\end{array}$ \\
\hline
\end{tabular}


Table continue

\begin{tabular}{|c|c|c|c|c|}
\hline Study & $\begin{array}{l}\text { Condition of } \\
\text { recording and } \\
\text { data length for } \\
\text { analysis }\end{array}$ & Derived HRV measures & $\begin{array}{l}\text { Secondary } \\
\text { outcomes (other } \\
\text { measures) findings }\end{array}$ & HRV and OSA findings \\
\hline $\begin{array}{l}\text { Liao et } \\
\text { al. }^{16}\end{array}$ & $\begin{array}{l}\text { ECG during } \\
\text { sleep ( } 9 \text { hours) }\end{array}$ & $\begin{array}{l}\text { RMSSD, SDNN, Log-HF, Log-LF, LF/ } \\
\text { HF }\end{array}$ & NA & $\begin{array}{l}\text { SDB group had significantly lower HF, RMSSD, SDNN, } \\
\text { and significantly higher LF/HF }\end{array}$ \\
\hline $\begin{array}{l}\text { Nisbet et } \\
\text { al. }{ }^{14}\end{array}$ & $\begin{array}{l}\text { ECG during } \\
\text { sleep (time not } \\
\text { specified) }\end{array}$ & $\begin{array}{l}\text { SDNN, RMSSD, LF (0.04 -0.15 Hz), } \\
\text { HF (0.15-0.4 Hz), Total power, LF/HF }\end{array}$ & $\begin{array}{l}\text { Urinary cathecolamines } \\
\text { were not different } \\
\text { between groups }\end{array}$ & $\begin{array}{l}\text { HF and total power were higher in the MS OSA } \\
\text { group compared to the control group while LF/ } \\
\text { HF were higher during all sleep stages. LF was not } \\
\text { different between the groups at any sleep stage. } \\
\text { SDNN was higher in the MS OSA group compared } \\
\text { to controls during REM sleep, while RMSSD was } \\
\text { higher MS OSA group compared to control during } \\
\text { NREM I/ } 2 \text { and REM sleep. No group differences } \\
\text { between mean NN }\end{array}$ \\
\hline
\end{tabular}

$A B I$, autonomic balance sleep index; ECG, electrocardiography; HRV, heart rate variability; HF, high frequency; HF/T, normalized value of high frequency; LF, low frequency; LF/HF, ratio of low frequency and high frequency; LF/T, normalized value of low frequency; MS, moderate to severe; NA, not applicable; OSA, obstructive sleep apnea; RDI, respiratory disturbance index; REM, rapid eye movement; SDB, sleep-disordered breathing; TF, total frequency; VLF, very low frequency

Table 3 Methodological quality of included studies determined using NewCastle Ottawa scale

\begin{tabular}{|c|c|c|c|c|}
\hline Study & Selection & Comparability & Outcomes & Total \\
\hline Aljadeff et al." & 2 & I & - & 3 \\
\hline Baharav et al. ${ }^{13}$ & 4 & I & - & 5 \\
\hline Chaidas et al. ${ }^{12}$ & 2 & 2 & - & 4 \\
\hline Kwok et al. ${ }^{15}$ & 5 & I & 2 & 8 \\
\hline Liao et al. ${ }^{16}$ & 4 & 2 & - & 6 \\
\hline Nisbet et al. ${ }^{14}$ & 5 & 2 & - & 7 \\
\hline
\end{tabular}

Assessment strategy: selection (max. 5 stars), comparability (max. 2 stars) and outcome (max. 3 stars); Range 0-10 stars

\section{Results}

\section{Description of studies}

First, the research identified a total of 2337 studies. Of this 2329 272 studies were removed as duplicates and after the title and abstract reading, 9 studies were selected, as shown at Figure 1. Then those 9 studies were critically evaluated and the final sample was 6 studies. The reasons for exclusion were absence of full text and the absence of control subjects.

\section{Studies characteristics}

From the literature research, six observational studies were included, which represent a sample size of 378 children with obstructive sleep apnea and 567 controls. Among the OSA children and controls, the majority were male. The earliest study was from $1997^{11}$ and the latest, 2014 ${ }^{12}$ Table 1 . Those studies were published in different countries: Greece ${ }^{12}$, Israel ${ }^{13}$, Australia ${ }^{14}$, China ${ }^{15}$ and USA. ${ }^{11,16}$ Of those selected studies, four ${ }^{13-16}$ analysed the heart rate variability with linear methods (time and frequency) and two, ${ }^{11,12}$ used a non-linear method (Poincaré Plot) of analysis Table 2. All of them selected the eletrocardiogram for registered, but time of recording varied: 260 seconds for each sleep stage, 60 minutes or not determined. Five $\mathrm{e}^{11,12,14-16}$ of them recorded HRV while the children were asleep and one ${ }^{13}$ recorded also at supine position but they were awake. Three studies ${ }^{12-14}$ searched for secondary outcomes, such as Ln-transformed morning urine norepinephrine-to-creatinine ratio for nocturnal sympathetic output measurement and respiratory measures, urinary catecolamines and respiratory disturbance index.

\section{Heart rate variability parameters}

HRV analysis comprehends linear and non-linear methods. The linear methods are divided in two domains: time domain and frequency domain. Variables of time domain provide information of time distribution over R-R intervals and frequency domain about power distribution. ${ }^{17}$ Non-linear methods of HRV analysis is less explored than linear methods, but they can provide entropy information, which is relevant in complex organisms. One study reported only frequency domain measures, while three studies used both linear methods (time and frequency). The last two studies used non-linear analysis.

\section{Frequency domain variables}

The most relevant frequency domain measures in our selected studies were LF, HF and LF/HF ratio.

\section{Low-frequency HRV}

From the four selected studies, ${ }^{13-16}$ that used the frequency analysis, two reported the absolute and normalised values, ${ }^{13,15}$ one reported only the absolute value ${ }^{14}$ and the other showed Log values ${ }^{16}$ Table 2. The results of normalised and absolute values show an overall nonsignificant effect, neither in absolute value 635.3 (95\% CI-160.0 to 1430.3 ) or normalised value 0.0136 (95\% CI-0.023 to $0.031) .^{15}$ For Log-values the results were the same: when adjusted for other variables (sex, race, age, BMI percentile, porcentage of REM sleep, snore status and sleep effiency), there was nonsignificant effect comparing moderate SDB with no SDB or clinically diagnosed SDB with no SDB. ${ }^{16}$ Corroborating for these results, Nisbet et al., ${ }^{14}$ demonstrate no diference between the groups during any sleep stage. However, unlike the other studies, Baharav et al., ${ }^{13}$ demonstrate an enhanced variability in the LF absolute value and normalised value observed in the OSA children in relation to controls subjects. Although the LF power was higher in the OSA group compared with controls for all states of measurement (sleep stages and awake), no statistical results were shown. 


\begin{tabular}{|c|c|c|c|c|c|c|c|}
\hline & 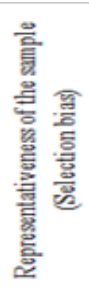 & 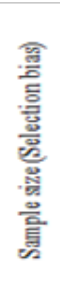 & 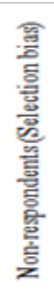 & 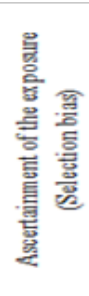 & 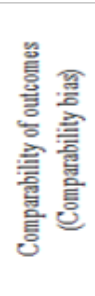 & 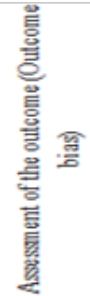 & 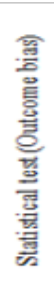 \\
\hline Aljadeff et al ${ }^{11}$ & - & - & - & 2 & 1 & - & - \\
\hline Baharav et al. ${ }^{13}$ & 1 & - & 1 & 2 & 1 & - & - \\
\hline Chaidas et al. ${ }^{12}$ & 1 & - & - & 1 & 1 & - & - \\
\hline Kwok et al. ${ }^{15}$ & 1 & 1 & 1 & 2 & 1 & 2 & - \\
\hline Liao et al. ${ }^{16}$ & 1 & 1 & - & 2 & 2 & - & - \\
\hline Nisbet et al. ${ }^{14}$ & 1 & 1 & 1 & 2 & 2 & - & - \\
\hline
\end{tabular}

Figure 2 Summary of risk of bias assessment: author judgments of each item of New-Castle Ottawa scale for the included studies.

\section{High-frequency HRV}

Two studies ${ }^{13,15}$ reported the absolute value and normalised value Table 2. The results of both studies show an overall nonsignificant effect between the groups, neither in absolute value $596.6(95 \%$ CI-107.7 to 1300.8$)$ or normalised value 0.016 (95\% CI-0.025 to $0.058),{ }^{15}$ but one of them didn't show numerical results. ${ }^{13}$ The only significant result of HF power was observed in normalised values at one study, ${ }^{13}$ where the HF/T were lower in the OSA group compared with the control group during all sleep-wake states, but only if compared during the awake state and REM sleep. When observed logvalues, Liao et al., ${ }^{16}$ showed lower HF in moderate SDB $(\mathrm{p}=0.025)$ and clinically diagnosed SDB $(\mathrm{p}=0.01)$ comparing to controls-while Nisbet et al., ${ }^{14}$ demonstrate higher HF and total power in the moderate to severe OSA compared to control group.

\section{Low-frequency to high-frequency ratio heart rate variability}

Four studies reported LF/HF ratio Table 2, but the results were discrepant. While one study showed nonsignificant effect between the groups -0.13 (95\% CI-0.71 to 0.45$),{ }^{15}$ one study ${ }^{14}$ evidenced that $\mathrm{HF} / \mathrm{LF}$ were lower in moderate-to-severe group $(0.4 \pm 0.05)$ compared to the control $(0.3 \pm 0.06)$ during NREM $3 / 4$ sleep, but nonsignificant effect between other sleep stages. Yet, two other studies evidenced that sympathovagal balance higher in the OSA group relative to the controls. Baharav et al., ${ }^{13}$ show diference while awake (Welch's two tailed t-test, $\mathrm{p}=0.005)$, slow wave sleep $(\mathrm{p}=0.035)$, during REM sleep $(\mathrm{p}=0.018)$, while Liao et al., ${ }^{16}$ demonstrate statistically diferences between moderate SDB $(\mathrm{p}<0.01)$ and clinically diagnosed SDB $(\mathrm{p}<0.0001)$ comparing to control group.

\section{Time domain variables}

Three studies showed time domain of heart rate variability measurement. RMSSD and pNN50 are variables that represent parasympathetic activity, because they analyze the adjacent R-R intervals while SDNN and SDANN can be obtained by long duration registers and represent both activity of sympathetic and vagal inputs. ${ }^{18}$ Kwok et al., ${ }^{15}$ showed nonsignificant results from SDNN 14.4 (95\%
CI-5.6 to 34.5), SDANN 6.6 (95\% CI-4.8 to 18.0) or RMSSD 14.7 (95\% CI-1.7 to 31.1); however, mean pNN50 was lower in OSA group than controls 8.6 (95\% CI 1.0 to 16.1). Similarly, Liao et al., ${ }^{16}$ demonstrate that RMSSD and SDNN were lower in clinically diagnosed SDB when compared with the control group $(\mathrm{p}=0.01$ and $\mathrm{p}=0.04$, respectively), although there were no significant results between moderate SDB group with controls. Surprisingly, another study ${ }^{14}$ reveals opposite results - SDNN was higher in the MS OSA group compared to controls during REM sleep as RMSSD was also higher during REM sleep and NREM 1/2. Nonsignificant results were found between groups at mean $\mathrm{NN}$.

\section{Non-linear method: poincaré plot}

The Poincare Plot is a scattergram of the R-R interval variability and represents the dynamic of HRV. ${ }^{12,18}$ Two studies ${ }^{11,12}$ used Poincaré Plot for HRV analysis and showed discrepant results. One study demonstrates that children with OSA and moderate-to-severe hypoxemia $(318.7 \pm 139.3 \mathrm{~ms})$ had significantly narrower plots than control subjects $(482.2 \pm 104.4 \mathrm{~ms}) .^{12}$ The other described that Poincaré plots of children with OSA tended to show greater next-interval dispersion following long R-R intervals (slow heart rates) than did those of control children. ${ }^{11}$

\section{Secondary outcomes}

Respiratory outcomes were expected because of the intrinsec relationship between HRV measures and respiratory frequency. HRV can be modulated by the respiratory cycle, a fenomenon called as respiratory sinus arrhythmia-RSA. ${ }^{19}$ Nevertheless, RSA can be demonstrated during obstructive sleep apnea episodes, which suggests that respiration modulates HR not only in physiological conditions, but also during obstructed breathing. ${ }^{20}$ Yet, a recent study also tried to use HRV and RSA as a diagnostic tool in adult patients with obstructive sleep apnea, but they couldn't isolate the effect of sleep apnea exclusively in RSA. ${ }^{21}$ At this review, two studies also reported respiratory measures, still one only demonstrated the respiratory disturbance index (RDI) as the other indicated the respiratory arousal index. Baharav et al., ${ }^{13}$ presented a positive correlation between ABI and RDI (Spearman rank correlation: $\mathrm{r}=0.8182$, two tailed $\mathrm{t}$-test: 
$p=0.0058$; with exclusion of the outlier, the correlation was: $r=0.8333$ and $\mathrm{p}=0.0083$ ). Furthermore, Chaidas et al., ${ }^{12}$ showed as well a negatively correlation between Poincaré plot and respiratory arousal index $(\mathrm{r}=-0.29 ; \mathrm{P}=0.03)$.

\section{Other findings}

Although a sympathetic measure as norepinephrine-to-creatinine ratio wasn't an expected outcome, to isolate the sympathetic effect is an interesting resource when the intention is to evaluate the modulation of the autonomic nervous system and its dysautonomia. That said, one study ${ }^{12}$ for nocturnal sympathetic output measurement collected a urine specimen in the morning for Ln-transformed morning urine norepinephrine-to-creatinine ratio analysis. The findings were that children with OSA had higher norepinephrine concentrations than controls subjects. Mean Ln-transformed morning urine norepinephrine-to-creatinine ratios were $4.5 \pm 0.6$ in OSA with moderate-to-severe hypoxemia, $4.2 \pm 0.6$ in OSA with mild hypoxemia and 3.8 \pm 0.4 in controls subjects. Yet, mean urine norepinephrine-tocreatinine ratios were $106.9 \pm 84.7$ in OSA with moderate-to-severe hypoxemia, $80.9 \pm 48.3$ in OSA with mild hypoxemia and $47.9 \pm 19.9$ $\mathrm{ng} / \mathrm{mg}$ in controls subjects. Another study also investigated the urinary cathecolamines, but there was no difference between OSA and control groups. $^{14}$

\section{Discussion}

This study goal was to investigate whether OSA children have autonomic impairment evaluated by HRV analysis, including linear and non-linear methods. In adults, OSA and cardiovascular diseases have similar risk factors, but OSA is also associated with cardiovascular morbidity and mortality, being a predisposing factor for cardiovascular pathologies independently of individual's demographic characteristics or risk markers. ${ }^{6}$ Yet, in children, there's no evidence of augmented for cardiovascular mortality, but OSA diagnosis is also accompanied of cardiovascular comorbidities.,22 In our review, we evidence that children with OSA may also present a diminished vagal tone and higher sympathetic responsiveness, which represents a sympathetic-parasympathetic imbalance. Another metanalysis using HRV spectral analysis tried to address this question. ${ }^{8}$ This metanalysis included four studies which represent a sample size of 518 control children and 272 chidren with OSA, and evidenced a possible dysautomia in those OSA children. An important highlight is sympathetic predominance was present especially during NREM stage 4 of sleep, but a diminished sympathetic activity was evidenced in day time. Authors suggested that perhaps OSA in children has a short-term effect, which differs from adult patients. ${ }^{8}$ Besides HRV assessment, a few studies also included a sympathetic index based on urine samples from OSA children and controls. ${ }^{12,14}$ This measure helps to identify sympathetic component isolate from parasympathetic influences, and can be used to assess sympathetic predominance in children. Yet, another study involving children with intermittent upper airway obstruction monitored morning urine norepinephrine and epinephrine and reveals higher sympathetic tone in those patients, which indicates that hypoxemia during sleep may implicate in sympathetic responsiveness. ${ }^{23}$

The strengths of this systematic review include sample size number, the use of strict methodological inclusion criteria, a quality assessment of included studies and consistent results. Sample size is an important element when minor participants are involved in research due to difficulties in recruitment and also data collection. Although a large sample size number, this review failed to unravel posible autonomic dysautomia or cardiovascular associated risk in those children due to discrepant results. Moreover, these results may be related to the age of children participants ranging of 3 to 13 years. Methodological discrepancies between studies are also a limiting factor since data length and condition of recording. These discrepancies can affect the accuracy of HRV analysis ${ }^{24}$ and mainly, the comparison of their results. Long 24-hour data collection includes metabolism and circadian cycle effects over HRV assessment and it's considered a "golden standard". 7 In summary, autonomic impairment is evidenced in children with obstructive sleep apnea, which can be associated with cardiovascular risk when adults. The mechanisms underlying the sympathovagal imbalance remains unclear, although hypoxia and hypercapnia derived from apnea episodes definitely play a role in physiopathology of OSA. Cathecolamines investigation is also a great measure to determine an increased sympathetic drive and responsiveness, and contributes for autonomic findings. Due to some discrepant results, more studies should be done to confirm this hypothesis. The difficulty of children recruitment is an important barrier for those studies, but autonomic tests involving respiratory maneuvers could be used to evaluate such patients. Thus, HRV analysis can be used as a risk marker or for therapeutic follow-up.

\section{Acknowledgments}

None.

\section{Conflicts of interest}

There was no conflict of interest for any of the authors in this study.

\section{Funding}

None.

\section{References}

1. Lim J, Lasserson TJ, Fleetham J, et al. Oral appliances for obstructive sleep apnea. Cochrane Database Syst Rev. 2004;18(4):CD004435.

2. Del Rosso LM. Epidemiology and diagnosis of pediatric obstructive sleep apnea. Curr Probl Pediatr Adolesc Health Care. 2016;46(1):2-6.

3. Bodenner KA, Jambhekar SP, Com G, et al. Assessment and treatment of obstructive sleep-disordered breathing. Clin Pediatr (Phila). 2014;53(6):544-548.

4. Kheirandish-Gozal L, Bhattacharjee R, Gozal D. Autonomic alterations and endothelial dysfunction in pediatric obstructive sleep apnea. Sleep Med. 2010;11(7):714-720.

5. Gozal D, Hakim F, Kheirandish-Gozal L. Chemoreceptors, baroreceptors, and autonomic deregulation in children with obstructive sleep apnea. Respir Physiol Neurobiol. 2013;185(1):177-185.

6. Jean-Louis G, Zizi F, Clark LT, et al. Obstructive sleep apnea and cardiovascular disease: role of the metabolic syndrome and its components. J Clin Sleep Med. 2008;4(3):261-272.

7. Shaffer F, McCraty R, Zerr CL. A healthy heart is not a metronome: an integrative review of the heart's anatomy and heart rate variability. Front Psychol. 2014;5:1040.

8. Kelmanson IA. Signs of sympathetic dominance in sleep and wake based on spectral analysis of heart rate variability in children with obstructive sleep apnea. Somnologie. 2014;18(3):194-201.

9. Moher D, Liberati A, Tetzlaff J, et al. Preferred Reporting Items for Systematic Reviews and Meta-Analyses: The PRISMA Statement. PLoS Med. 2009;6(7):e1000097. 
10. Modesti PA, Reboldi G, Cappuccio FP, et al. Panethnic differences in blood pressure in Europe: a systematic review and meta-analysis. PLoS One. 2016;11(1):e0147601.

11. Aljadeff G, Gozal D, Schechtman VL, et al. Heart rate variability in children with obstructive sleep apnea. Sleep. 1997;20(2):151-157.

12. Chaidas K, Tsaoussoglou M, Theodorou E, et al. Poincaré Plot width, morning urine norepinephrine levels, and autonomic imbalance in children with obstructive sleep apnea. Pediatr Neurol. 2014;51(2):246251.

13. Baharav A, Kotagal S, Rubin BK, et al. Autonomic cardiovascular control in children with obstructive sleep apnea. Clin Auton Res. 1999;9(6):345-351.

14. Nisbet LC, Yiallourou SR, Nixon GM, et al. Nocturnal autonomic function in preschool children with sleep-disordered breathing. Sleep Med. 2013;14(12):1310-1316.

15. Kwok KL, Yung TC, Ng DK, et al. Heart rate variability in childhood obstructive sleep apnea. Pediatr Pulmonol. 2011;46(3):205-210.

16. Liao D, Li X, Rodriguez-Colon SM, et al. Sleep-disordered breathing and cardiac autonomic modulation in children. Sleep Med. 2010;11(5):484488 .

17. Tracy LM, Iannou L, Baker KS, et al. Meta-analytic evidence for decreased heart rate variability in chronic pain implicating parasympathetic nervous system dysregulation. Pain. 2016;157(1):729.
18. Vanderlei LC, Pastre CM, Hoshi RA, et al. Basic notions of heart rate variability and its clinical applicability. Rev Bras Cir Cardiovasc. 2009;24(2):205-217.

19. Katona PG, Jih F. Respiratory sinus arrhythmia: a noninvasive measure of parasympathetic cardiac control. J Appl Physiol. 1975;39(5):801-805.

20. Bonsignore MR, Marrone $\mathrm{O}$, Insalaco G, et al. The cardiovascular effects of obstructive sleep apnoeas: analysis of pathogenic mechanisms. Eur Respir J. 1994;7(4):786-805.

21. Sani SN. Using respiratory sinus arrhythmia to detect obstructive sleep apnea. Health Technol. 2017;7(2-3):207-212.

22. Gozal D, Hakim F, Kheirandish-Gozal L. Chemoreceptors, baroreceptors, and autonomic deregulation in children with obstructive sleep apnea. Respir Physiol Neurobiol. 2013;185(1):177-185.

23. Kaditis AG, Alexopoulos EI, Damani E, et al. Urine levels of cathecolamines in Greek children with obstructive sleep-disordered breathing. Pediatr Pulmonol. 2009;44(1):38-45.

24. Taralov ZZ, Terziyski KV, Kostianev SS. Heart rate variability as a method for assessment of the autonomic nervous system and the adaptations to different physiological and pathological conditions. Folia Med (Plovdiv). 2015;57(3-4):173-180. 